\title{
Evaluation of anti-measles and anti-mumps vaccination coverage in a cohort of youth in South-Centre of Sicily, Italy
}

\author{
Claudia Lo Magno, Liborio Bellomo, Rosalba Collodoro, Giuseppina Di Forti \\ Virology Unit, ASP 2, Caltanissetta, Italy
}

\section{Summary}

This study examined a cohort of young people from South Centre Sicily, Italy, in order to evaluate anti-measles anti-mumps vaccination coverage. It is shown that, in proportion, an antibody protection against mumps is greater than an antibody protection against measles and also it causes acute episodes in some subjects vaccinated.

\section{Introduction}

A close examination of the data in the literature shows that the antibody protection at the age of 24-36 months in our country (Sicily, Italy) is very high, even more than $95 \%$, for vaccines against anti Poliovirus, Corynebacterium diphtheriae, Clostridium tetani, Bordetella pertussis, Hepatitis B virus, Haemophilus influenzae B, Pneumococcus, and, even if relevant, there are still no satisfactory covers for Measles virus, Mumps virus, Varicella virus and Neisseria meningitidis. It has been also noted that the antibody in adults are frequently low (4,5); in fact it is ascertained that the duration and the level of vaccine protection is not unlimited in time.

At this regard we note that critical elements of vaccination programs are: i) inadequate recommendation and promotion of recovery (catch-up) at the end of the completion of a vaccination course

Correspondence: Claudia Lo Magno, U.0. Virologia, ASP 2, Via Santo Spirito 57 , Caltanissetta, Italy.

Tel.: +39.0934 .559555 - Fax: +39.0934 .559555 .

E-mail: clalomagno@gmail.com

Key words: vaccination, Measles virus, Mumps virus.

Contributions: the authors contributed equally.

Conflict of interest: the authors declare no potential conflict of interest.

Received for publication: 16 February 2015.

Accepted for publication: 29 May 2015.

(C) Copyright C. Lo Magno et al., 2015

Licensee PAGEPress, Italy

Microbiologia Medica 2015; 30:5103

doi:10.4081/mm.2015.5103

This article is distributed under the terms of the Creative Commons Attribution Noncommercial License (by-nc 3.0) which permits any noncommercial use, distribution, and reproduction in any medium, provided the original author(s) and source are credited. already started; ii) the supply of some vaccines limited to subgroups of populations at risk for the disease, for profession and travellers (7).

On March 23, 2011, in Italy, the new plan for the eradication of measles and congenital rubella from 2010 to 2015 was approved by the State-Regions Conference in accordance with those objectives between Europe and the World Health Organization (WHO) for 2015 $(8,9,10)$.

The objectives were not achieved at all, so much so that there have been outbreaks in several Italian regions (1) (see also: www. epicentro.iss).

The etiological agents of measles and mumps are viruses with not segmented single-stranded RNA with negative polarity belonging to the family Paramixoviridae.

The measles virus is pathogenic only for man and the disease it causes is one of the diseases with the highest infectivity.

There is only one serotype of the virus and more than twenty genotypes. Studies conducted in Italy between 2009 and 2010 showed that the genotypes circulating are predominantly D4, D8 and B3 (3).

In 2002 there was in Italy a large outbreak of measles with probably about 40,000 cases, more than 1000 hospitalized, 23 encephalitis and 4 deaths reported (Italian Ministry of Health). Measles can be a serious disease with fearful complications, such as: SSPE (subacute sclerosing panencephalitis), encephalitis, pneumonia, etc.

However, the data might be affected by underestimation for failure to report.

Mumps is a widespread disease in children and adolescents and is characterized mainly by a maximum suffering of the salivary glands. Only one serotype has been recognized but several genotypes according to the WHO classification of 2012 are: A, B, C, D, F, $\mathrm{G}, \mathrm{H}, \mathrm{I}, \mathrm{J}, \mathrm{K}, \mathrm{L}, \mathrm{N}$. This typing is based on the reconstitution of the sequence of the gene coding for the synthesis of proteins small hydrophobic (SH).

The virus mainly affects humans but can also infect the monkey and the chick embryo.

The mumps virus continues to circulate in our country, causing cyclic epidemic peaks that predominantly affect childhood age and teen age; in 2000 there has been an epidemic with over 37,000 cases reported. As for measles the cases of mumps are certainly underestimated (Italian Ministry of Health).

The course of mumps can be complicated by aseptic meningitis, pancreatitis, permanent deafness, orchitis etc.

The vaccine against measles-mumps-rubella (MMR) is obtained with live viruses but attenuated. It is administered subcutaneously (Italian Ministry of Health).

The vaccination schedule consists of two doses of MMR: the first dose between 12 and 15 months of age; the second dose at 5-6 years of age (6). 


\section{Materials and Methods}

Our study focused on patients tested from 2011 to 2013, with a positive history for vaccination measles-mumps-rubella and born between 1993 and 2001. The aim was to assess the actual persistence of protective antibody against of measles and mumps in south-central Sicily, which is the catchment area of this unit of Virology. It was not taken into account the protection rubella antibody is because the persistence of antibodies over time is known: according to data in the literature it seems that $93 \%$ of vaccines are protected in time (2). Patients who did not respond to the characteristics required for inclusion in the study were also excluded from our study.

The test used is the DRG and uses an enzyme immunoassay (EIA) method for the detection of Immunoglobulin G (IgG) and immunoglobulin $\mathrm{M}(\mathrm{IgM})$ respectively for Measles and Mumps viruses.

The test for the detection of IgM is to capture of immunoglobulins by monoclonal antibodies antihuman IgM present in the solid phase. A subsequent incubation with the specific antigen, measles and mumps respectively, complexes with peroxidase-conjugated monoclonal select IgM antibodies specific for the antigen and detectable by addition of the substrate for the enzyme. When the enzymatic reaction is terminated by the addition of a solution of sulphuric acid, the colour turns to yellow. The developed colour is proportional to the quantity of specific antibodies present in the serum.

The test used for the detection of IgG is a methodology Enzyme Linked Immuno Sorbent Assay (ELISA). The antigen of the specific virus purified and inactivated is bound to the solid phase; by incubation with diluted human serum, specific immunoglobulins bind to the antigen. After the necessary washing, useful for removing proteins that have not reacted, the incubation with the conjugate composed of monoclonal anti-human IgG labelled with peroxidase takes place.

A colour reaction will be developed and it is proportional to the concentration of the specific antibodies present in the serum sample.

\section{Results}

The results obtained through the study are summarized in Tables 1 and 2 and in Figures 1-4.

Table 1. Results obtained by testing patients for IgG and IgM anti-measles and anti-mumps antibodies.

\begin{tabular}{|c|c|c|c|c|c|c|c|c|}
\hline \multirow{2}{*}{ Samples } & \multicolumn{4}{|c|}{ Anti-measles } & \multicolumn{4}{|c|}{ Anti-mumps } \\
\hline & IgG & $\%$ & $\operatorname{Ig} M$ & $\%$ & $\operatorname{Ig} G$ & $\%$ & IgM & $\%$ \\
\hline Positive & 39 & 59 & 7 & 11 & 26 & 65 & 0 & 0 \\
\hline Negative & 27 & 41 & 59 & 89 & 14 & 35 & 40 & 100 \\
\hline Total & 66 & & 66 & & 40 & & 40 & \\
\hline
\end{tabular}

\section{Measles IgG}

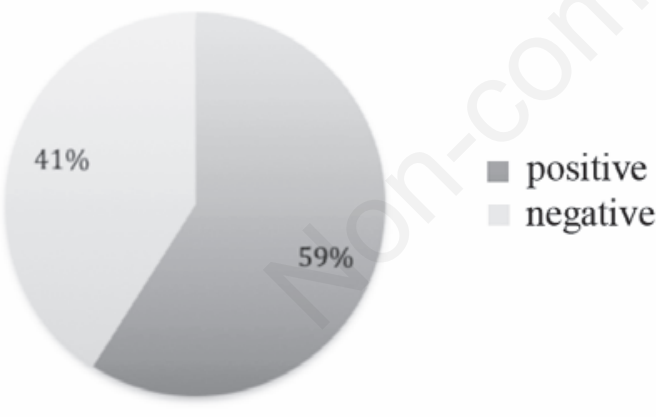

\section{Mumps IgG}

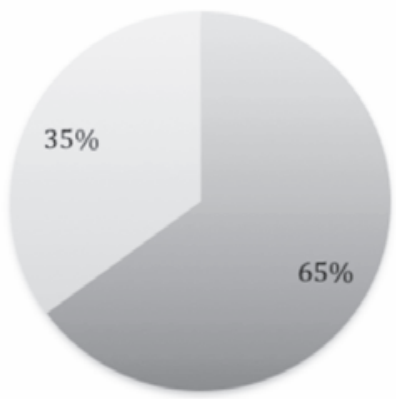

positive

negative
Measles IgM

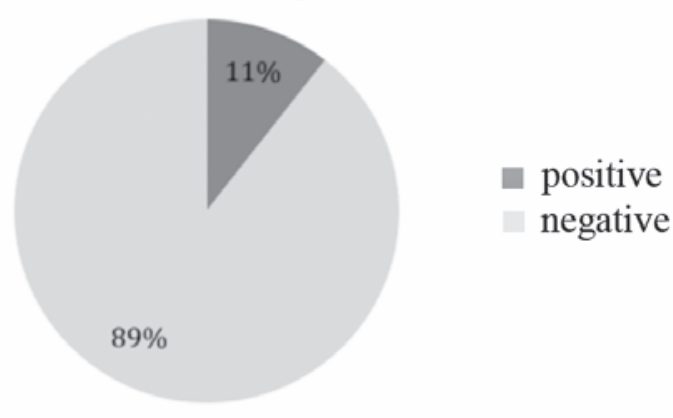

Mumps IgM positive

negative

Figure 1. Anti-measles and anti-mumps IgG and IgM antibodies. 
A

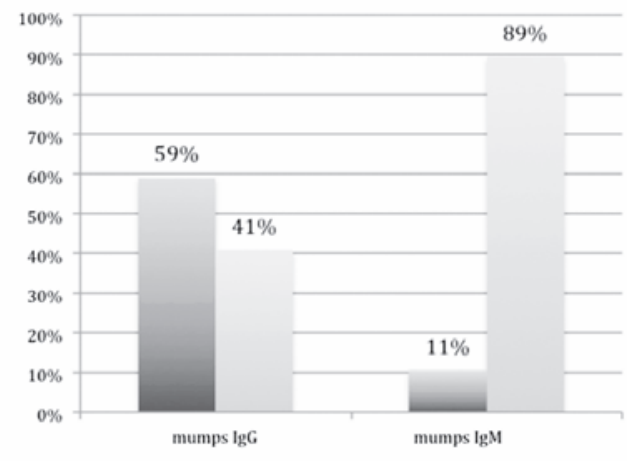

C

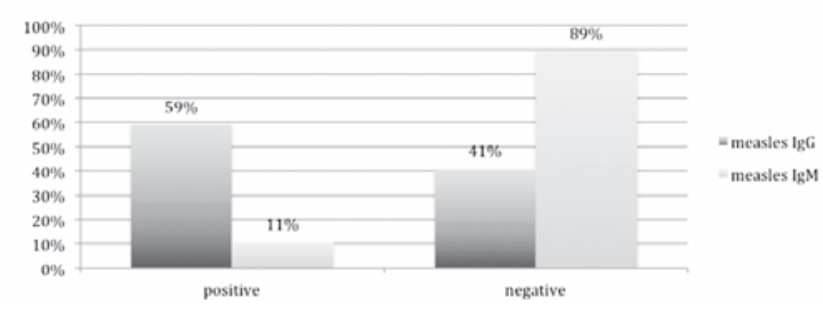

B

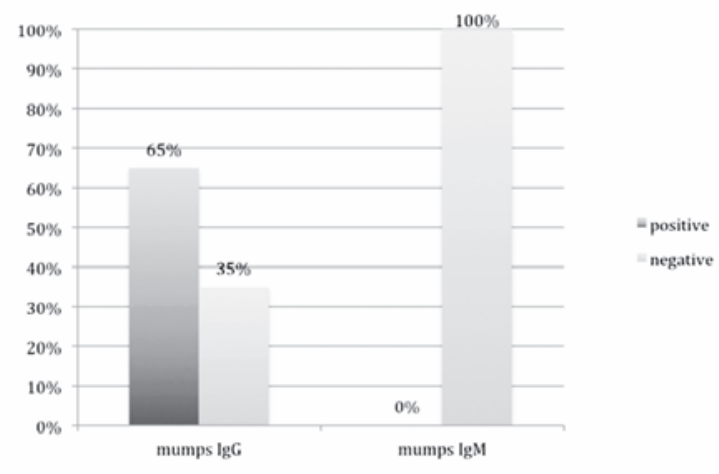

D

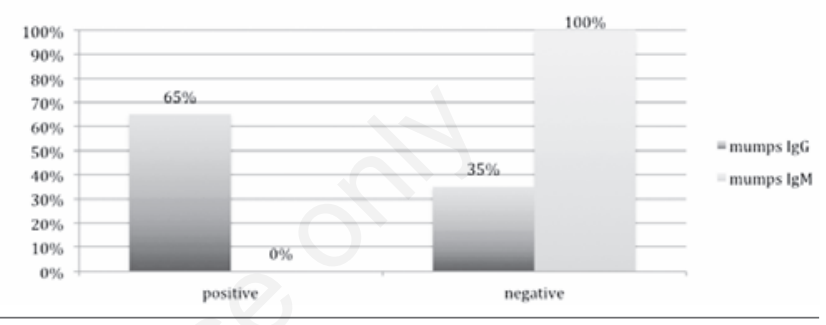

Figure 2. Comparisons: anti-measles IgG positive-negative and anti-measles IgM positive-negative (A); anti-mumps IgG positive-negative and anti-mumps IgM positive-negative (B); anti-measles positive IgG-IgM and anti-measles negative IgG-IgM (C); anti-mumps positive IgG-IgM; anti-mumps negative IgG-IgM (D).

A

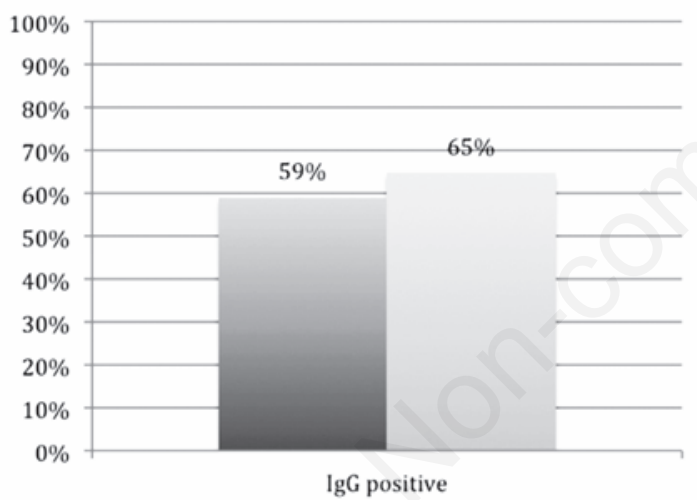

C

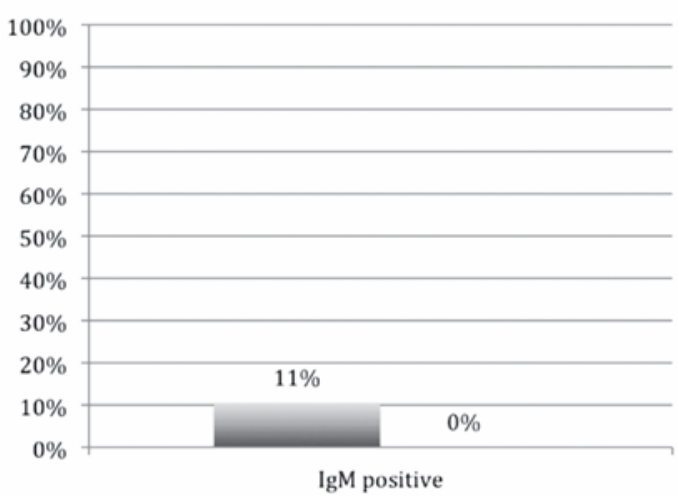

B

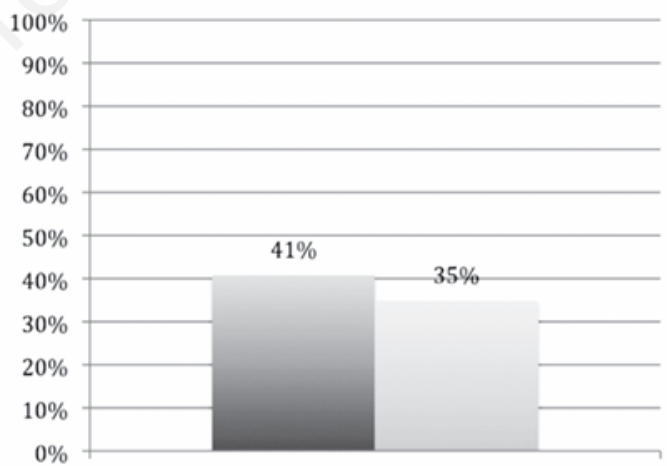

$\lg$ negative

D

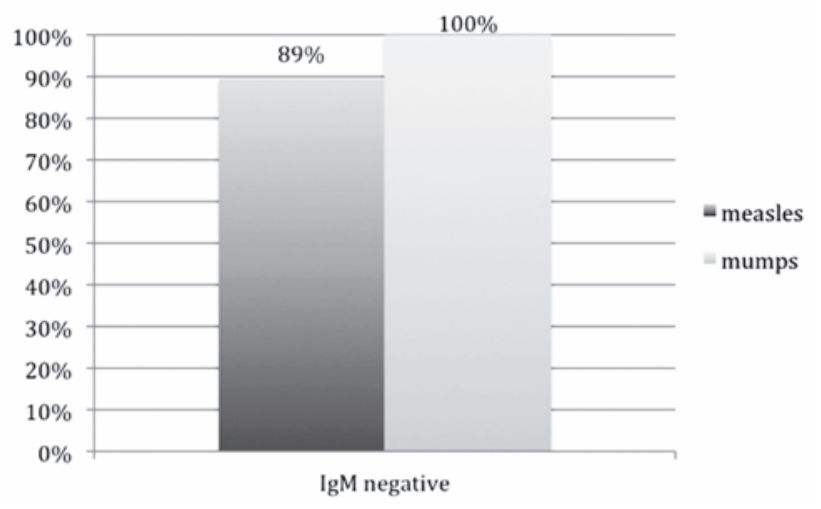

Figure 3. Comparisons: anti-measles/mumps IgG positive (A); anti-measles/mumps IgG negative (B); anti-measles/mumps IgM positive (C); anti-measles/mumps IgM negative (D). 

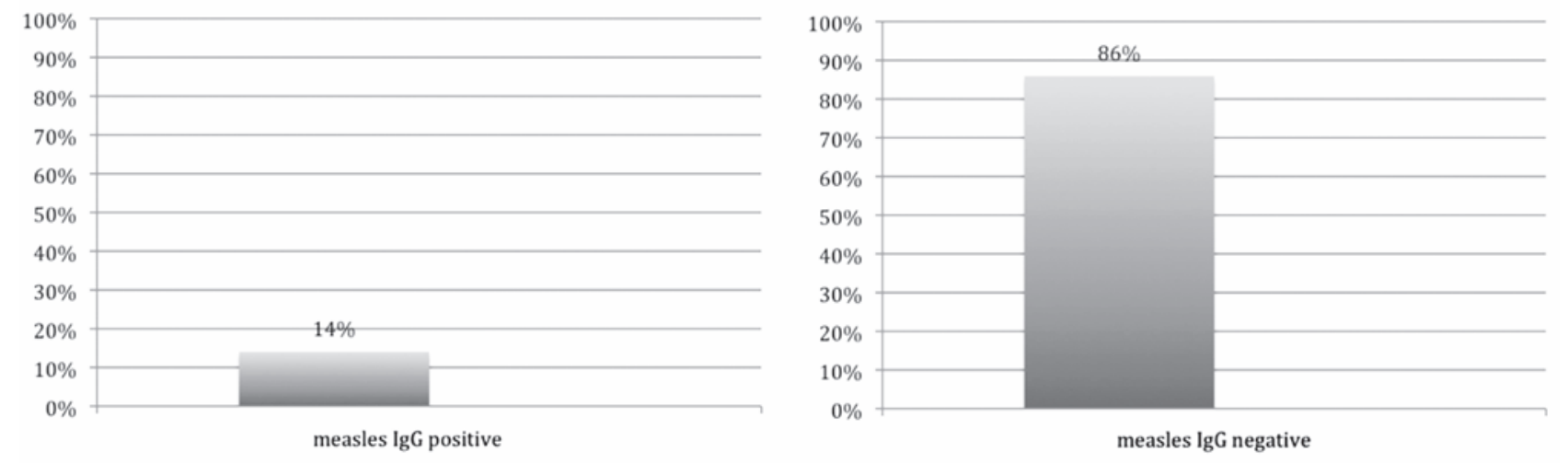

Figure 4. Anti-measles IgM positive with IgG positive and anti-measles IgM positive with IgG negative.

Namely, it was found that: $59 \%$ of patients tested is positive for IgG anti-measles antibodies; $65 \%$ of patients tested is positive for IgG antimumps antibodies; $11 \%$ of patients tested is positive for IgM anti-measles antibodies; no patient is positive for IgM anti-mumps antibodies.

Among $41 \%$ of patients negative for IgG anti-measles antibodies, some patients tested developed an acute infection.

Of seven patients with acute disease only one (14\%) had antibodies of the IgG class, while the remaking $86 \%$ was negative.

\section{Discussion and Conclusions}

On the basis of the obtained data, it is reasonable to believe that: i) there was no evidence of acute mumps, not because patients were all protected, but probably because the virus was less circulating around the time of observation; ii) the measles virus seems instead to be more present in the population of the basin; iii) about two out of three of the patients measles vaccinated maintain protection at least until the age of youth; iv) one out of three is defenceless, thus ensuring, among other things, recirculation of the virus; v) a higher percentage (6\%) of subjects vaccinated against mumps compared to measles vaccinated, still have protection at least at the time of our observation.

In the future, it would be appropriate to evaluate the antibody in older subjects compared to the sample that was taken into consideration and the opportunity to propose a more incisive appeal in order to protect patients over time.

\section{References}

1. Bella A, Filia A, Del Manso M, et al. Morbillo \& Rosolia News, Ottobre 2014. Available form: http://www.epicentro.iss.it/problemi/morbillo/bollettino/R\&M_News_2014_11.pdf

2. Cologni L, Belotti L, Bacis M, et al. Measles, mumps, rubella and
Table 2. Anti-measles IgM positive patients were tested for IgG positive and negative antibodies.

\begin{tabular}{lcc} 
Samples & $\begin{array}{c}\text { Anti-measles } \\
\text { IgM positive }\end{array}$ & $\%$ \\
IgG positive & 1 & 14 \\
IgG negative & 6 & 86 \\
\hline Total & 7 & 100 \\
\hline
\end{tabular}

varicella: antibody titration and vaccinations in a large hospital] Ital Med Lav Ergon 2012; 34: 272-4. [Article in Italian].

3. Filia A, Tavilla A, Bella A, et al. Measles in Italy, July 2009 to September 2010. Available from: http://www.eurosurveillance.org/ ViewArticle.aspx?ArticleId=19925

4. Filia A, Giambi C, Bella A, et al. Sorveglianza del morbillo e della rosolia congenita e stato di avanzamento del Piano di Eliminazione, gennaio 2009. Not Ist Super Sanità 2009; 22: ii-iv.

5. Gruppo di lavoro ICONA. ICONA 2008: indagine di copertura vaccinale nazionale nei bambini e negli adolescenti. Rapporti ISTISAN 09/29 Roma: Istituto Superiore di Sanità; 2009.

6. Ministero della Sanità. Nuovo calendario delle vaccinazioni obbligatorie e raccomandate per l'età evolutiva. Gazzetta Ufficiale n. 87 del 15 aprile 1999.

7. Regione Sicilia. Calendario vaccinale per la vita. Modifica ed integrazione del Calendario Vaccinale della Regione Sicilia adottato con D.A. $n^{\circ}$ 01819/10.

8. Spadea A, Morciano L, Serino L, Franco E. Vaccination against measles, mumps and rubella in a Roma people camp in Rome. Ig San Pubbl Italy 2011; 67: 233-40.

9. World Health Organization. Expanded programme on immunization. The EPI Coverage Survey, training for mid level managers. Geneva: WHO; 1991. (WHO/EPI/MLM/91.10).

10. WHO Regional Office For Europe. Operational targets for EPI diseases. Copenhagen; WHO Regional Office for Europe, 1996. (EUR/HFA target 14, EUR/CMDS 0101 11). 